\title{
Activation of the dorsal septum increases alcohol consumption in male C57BL/6J mice.
}

Harold L. Haun, PhDa; Shannon L. D’Ambrosioa, Thomas L. Kash, PhDa,b

aBowles Center for Alcohol Studies, University of North Carolina at Chapel Hill, Chapel Hill, North Carolina, 27599.

„Department of Pharmacology, University of North Carolina School of Medicine, Chapel Hill, North Carolina, 27599.

\section{CORRESPONDING AUTHOR:}

T. L. Kash (tkash@email.unc.edu)

Bowles Center for Alcohol Studies

University of North Carolina at Chapel Hill

CB 7178 Thurston Bowles Building

104 Manning Drive

Chapel Hill, NC 27599 


\begin{abstract}
Binge drinking is a common pattern of excessive alcohol consumption associated with Alcohol Use Disorder (AUD) and unraveling the neurocircuitry that promotes this type of drinking is critical to the development of novel therapeutic interventions. The septal region was once a focal point of alcohol research yet has seen limited study over the last decade in relation to binge drinking. Numerous studies point to involvement of the dorsal septum (dSep) in excessive drinking and withdrawal, but few studies have manipulated this region in the context of binge drinking behavior. The present experiments were primarily designed to determine the effect of chemogenetic manipulation of the dSep on binge-like alcohol drinking in male and female C57BL/6J mice. Mice received bilateral infusion of $A A V s$ harboring hM4Di, hM3Dq, or mCherry into the dSep and subjects were challenged with systemic administration of clozapine- $N$-oxide $(C N O ; 3 \mathrm{mg} / \mathrm{kg})$ and vehicle (saline; $0.9 \%$ ) in the context of binge-like alcohol consumption, locomotor activity, and sucrose drinking. CNO-mediated activation (hM3Dq) of the dSep resulted in a significant increase in binge-like alcohol consumption, locomotor activity, and sucrose intake in male mice. DSep activation promoted sucrose drinking in female mice, but alcohol intake and locomotor activity were unaffected. Conversely, silencing (hM4Di) of the dSep modestly decreased locomotor activity in males and did not influence alcohol or sucrose intake in either sex. Lastly, CNO was without effect in mCherry-expressing control groups. These data support a role for the dSep in promoting excessive, binge-like drinking behavior in a sex-dependent fashion and suggests a broad role for the region in the modulation of locomotor activity as well as general appetitive behavior such as sucrose drinking.
\end{abstract}




\section{INTRODUCTION}

The COVID-19 pandemic has had a palpable negative impact on mental health and incidences of binge drinking have seen a concomitant rise in the US [1,2]. Binge drinking is defined as the rapid consumption of alcohol such that blood alcohol concentrations (BAC) exceed the 0.08 $\mathrm{g} / \mathrm{dL}$ legal limit of intoxication in a relatively short period of time [3-5]. This type of drinking is the most common pattern of excessive alcohol consumption and is associated with an increased risk for the development of an alcohol use disorder (AUD) [6-10]. Alcohol dependence and AUDs create a sizeable social and economic impact amounting to roughly $\$ 249$ billion annually and is a leading cause of preventable mortality [11-13]. However, treatment strategies are severely lacking and a more thorough understanding of the neurobiological processes that govern excessive, uncontrolled alcohol drinking is necessary to meet this goal.

Preclinical models including the Drinking-in-the-Dark (DID) paradigm serve as a platform for pharmacological and circuit-level interrogation of systems that drive binge drinking, paving the way for the development of much needed novel pharmacotherapies [14-16]. Subcortical limbic structures such as the septal complex, hippocampus (HPC), amygdala (AMY), and nucleus accumbens (NAc) are of interest in promoting binge drinking behavior. In fact, researchers have demonstrated involvement of the HPC [17,18], AMY [19,20], and NAc [21,22] in excessive binge-like drinking behavior. However, no studies to date have manipulated the septal complex in the context of binge drinking and this is an intriguing avenue for further study given the role of this region in various alcohol related behaviors.

The septal region was one of the first structures identified by Olds and Milner to be responsive to electrical self-stimulation protocols, which suggested involvement in reward-related behavior [23]. Around the same time, the septum garnered much attention as lesion resulted in the phenomenon known as "septal rage" where rodents display highly aggressive behavior [24,25]. Much progress has been made since this time and the septum has been found to be an integral node in circuitry mediating spatial navigation and movement, reward processing, social behaviors, mood/affect, and a key component in generating theta rhythms and oscillations [26]. Indeed, patients diagnosed with an AUD display many behavioral disturbances consistent with septal function, such as movement disorders [27], reward-deficit biased behavior [28], increased aggressiveness and negative affective behavior [29,30], and altered theta [31]. Given these functions, it is likely that the septum plays a role in the various behaviors displayed in AUD and is a candidate for further study.

Interestingly, study of the septum in the context of AUD is somewhat limited. Human imaging studies found decreased septal volume in patients with an AUD or Wernicke-Korsakoff Syndrome $[32,33]$. Preclinical studies canvasing the effect of alcohol drinking on expression of the immediate early gene, c-fos, used this marker as a proxy for neuronal activity and found decreased expression following systemic alcohol challenge and voluntary consumption [34,35]. Further electrophysiological studies revealed that alcohol enhanced GABAergic activity to promote septal inhibition in rats with a history of drinking [36,37]. These findings suggest that the septum is responsive to acute alcohol challenge and that neuroadaptations occur with chronic consumption. Furthermore, c-fos activity is increased within the septum during withdrawal [38], suggesting engagement of the septal complex during a time when relapse-like behavior is observed. This general hypothesis is supported by work from the Aston-Jones lab that found increased septal cfos activity during cocaine-seeking behavior [39]. Furthermore, inactivation of the septum blocked contextual- and cue-induced reinstatement for cocaine [40], and attenuates motivated responding [41], supporting a role for the septum in relapse-like behavior. 
While novel techniques within the preclinical research toolkit have advanced greatly in the last decade, studies targeting the septum have been largely absent from modern literature in the alcohol field. To fill this void, we tested the role of the dorsal septum (dSep) in the context of binge-like alcohol drinking behavior in male and female C57BL/6J mice using a chemogenetic approach. The primary objective of this study was to assess the role of the dSep on alcohol intake, however, the septal region also modulates locomotor activity and general reward related behavior. Thus, additional experiments were conducted to determine the contribution of the dSep to locomotor activity in an open field task and on sucrose consumption.

\section{MATERIALS AND METHODS}

\subsection{Subjects}

Male and female ( $\mathrm{N}=30 / \mathrm{sex}) \mathrm{C} 57 \mathrm{BL} / 6 \mathrm{~J}$ mice (Jackson Laboratories, Bar Harbor, ME) at 10 weeks of age were singly housed and tested in a temperature and humidity controlled AAALAC approved facility on a reverse 12-hr light/dark cycle. For all experiments, rodent chow (Isopro, RMH300) and water were provided ad libitum and mice were treated in accordance with both the NIH Guide for the Care and Use of Laboratory Animals and the Institutional Animal Care and Use Committee at UNC.

\subsection{Surgical Procedures}

Mice were anaesthetized with isoflurane $(2 \%)$ and the AAV construct was bilaterally infused into the dSep (AP: + 0.8, ML: +/- 0.3, DV: -3.8) as depicted in Figure 1A. A total volume of $250 \mathrm{~nL}$ of hM4Di, hM3Dq, or mCherry was infused into the dSep using a 0.5 uL Hamilton Neuros syringe at a flow rate of $0.05 \mathrm{uL} / \mathrm{min}$ for $5 \mathrm{~min}$. The syringe was then left in place during a 5 min diffusion period and retracted over 5 min as previously described [42]. Viral constructs obtained from Addgene for use in these experiments were AAV8-hSyn-hM4Di-mCherry (\#50475), AAV8-hSynhM3Dq-mCherry (\#50474), and AAV8-hSyn-mCherry (\#114472). Post-operative care consisted of a single prophylactic treatment with buprenorphine $(0.1 \mathrm{mg} / \mathrm{kg})$ and 3 days of maintenance on a liquid acetaminophen solution during recovery.

\subsection{Behavioral Testing}

After surgery, mice were given 2 weeks to recover undisturbed in the home cage and then were habituated to intraperitoneal (ip.) injections of $0.9 \%$ saline $(0.01 \mathrm{ml} / \mathrm{kg})$ once daily for a week. Saline injections served as vehicle for all studies. After habituation to injections, mice began the alcohol drinking phase of testing, which occurred over 2-3 consecutive weeks. Following the final week of alcohol drinking, mice were left undisturbed in their home cage for 2 weeks. Mice were then tested in an open field arena to assess locomotor activity. The following week, mice began the sucrose drinking phase of the experiment for 2 consecutive weeks. A diagram depicting the timeline of experimental testing is shown in Figure 1C.

\subsection{Drinking Procedures}

Alcohol bottles were presented 3-hrs into the dark cycle during 2-hr limited-access drinking sessions for 5 consecutive days (Mon-Fri). Mice received daily saline injections 30 -min prior to alcohol drinking. This modified drinking in the dark (DID) procedure was selected because it generates binge-like levels of alcohol drinking and BACs [43]. Most importantly, vehicle/drug testing can be conducted in a within-subjects fashion during a single test week, minimizing the potential for drinking differences or environmental disturbances between test weeks that is 
possible in the typical DID model. After habituation to alcohol drinking and saline injections (1-2 weeks), average weekly alcohol intake was calculated for each mouse and used to separate subjects evenly into drug treatment groups (vehicle vs CNO) in a balanced within-subjects design. During the Test week, all mice received vehicle injections prior to drinking on Day 1 and CNO testing occurred across Day 2-5 in a crossover design such that each subject received a single dose of CNO (3 mg/kg; HelloBio, HB6419). CNO was prepared daily in saline and delivered at $0.01 \mathrm{ml} / \mathrm{kg}$ volume $30-\mathrm{min}$ prior to drinking.

Sucrose drinking was assessed in an identical fashion to alcohol drinking. Briefly, mice were given access to a single bottle containing sucrose (1\%; w/v) for 2-hr a day, 3-hr into the dark cycle, Monday-Friday for two consecutive weeks. Testing occurred during the second week of drinking across Days 2-5 in a counterbalanced, crossover design.

\subsection{Open Field Testing}

Mice were left undisturbed in their home cage for 2 weeks following alcohol drinking and then activity chambers were used to assess locomotor activity. Subjects were tested in a SuperFlex open field arena (Omnitech Electronics, Accuscan, Columbus, $\mathrm{OH}$ ) and proprietary Fusion v6.5 software was used to track beam breaks to determine total distance traveled during 30-min testing sessions. Briefly, the open field arena measured $60 \mathrm{~cm}$ wide $\times 60 \mathrm{~cm}$ long $\times 40 \mathrm{~cm}$ deep and a single light was positioned above the center of the apparatus ( $500 \mathrm{~lx})$. All mice were habituated to travel outside of the colony room for testing by placing cages on a covered cart and transporting to the behavioral testing room where they remained undisturbed for 8-hrs. The following day, mice were transported to the behavioral testing room, given a 2-hr acclimation period, then placed into the locomotor activity apparatus 30-min after vehicle injection. The goal of this experiment was to assess the effect of dSep inactivation/activation on locomotor behavior in a within-subjects design. Thus, a single session was used to habituate all mice to the locomotor apparatus prior to testing to control for novelty and order effects. Mice were handled in an identical fashion the following 2 days and tested with vehicle or $\mathrm{CNO}$ in a counterbalanced, crossover design. Distance traveled $(\mathrm{cm})$ was measured in 1-min bins for 30 minutes during the two testing sessions and cumulative distance traveled was analyzed. Additionally, cumulative time spent in the center (10 $\mathrm{cm}$ ) of the open field arena was collected to assess effects on anxiety-like behavior.

\subsection{Immunohistochemistry}

Upon completion of behavioral testing, all mice were deeply anaesthetized with Avertin (250 $\mathrm{mg} / \mathrm{kg}$; ip.) and transcardially perfused with ice cold saline $(15 \mathrm{~mL})$ followed by $4 \%$ paraformaldehyde (PFA; $15 \mathrm{~mL}$ ). Brains were extracted and post-fixed in PFA for 24-hrs. Tissue was sliced in $40 \mathrm{uM}$ sections using a Vibratome and serial sections containing the entirety of the dSep were processed for immunohistochemistry to visualize the mCherry tag. Tissue was washed in 1xPBS, permeabilized in $0.5 \%$ Triton X-100 for 30-min, and blocked in $0.1 \%$ Triton X-100 and Normal Donkey Serum (NDS; 10\%) for 1-hr. Tissue was incubated for 24-hr in the primary antibody solution that consisted of the blocking solution and mouse anti-RFP (1:500; Rockland Immunohistochemicals). The following day, tissue was washed in 1xPBS and incubated in a secondary solution that consisted of Alexa-Fluor 594 donkey anti-mouse (1:200; Jackson Immuno) in $0.1 \%$ Triton X-100 for 2-hr. Tissue was washed in 1XPBS, mounted on Permafrost Plus slides, and coverslipped for Vectashield Hardset with DAPI. Slides were imaged on a Keyence microscope and viral expression was verified within the dSep through visualization of mCherry within the target region. A depiction of the general viral footprint and spread within the dSep is shown in Figure $1 \mathbf{A}$ and a representative image of mCherry expression is shown in Figure 1B. 


\subsection{Statistical Analysis}

The primary dependent variables for drinking experiments were alcohol intake $(\mathrm{g} / \mathrm{kg})$ and sucrose intake $(\mathrm{mL} / \mathrm{kg})$. Alcohol and sucrose drinking data after vehicle and CNO challenge were analyzed by ANOVA, with Sex and Virus (hM4Di; hM3Dq; mCherry) as between-subjects factors and Drug (Vehicle; $\mathrm{CNO}$ ) as a repeated factor. Individual drinking values for vehicle and CNO testing days were then used to calculate the percent change in intake relative to vehicle ([(CNO-Vehicle) / (Vehicle) ] ${ }^{\star} 100$ ). These data were then analyzed by ANOVA with Sex and Virus (hM4Di; hM3Dq; mCherry) as between-subjects factors and Drug as a repeated measure. For open field testing, cumulative locomotor activity and center time were analyzed by ANOVA with Sex and Virus as between-subjects factors and Drug as a repeated measure. Significant factor interactions were further evaluated with planned post hoc comparisons with Holm-Sidak corrections for effect of CNO treatment relative to vehicle within each experimental condition. Alpha was set to $p<0.05$ for all analyses. A total of 8 mice were excluded from analysis due to unilateral AAV expression visualized by the mCherry tag within the dSep.

\section{RESULTS}

\subsection{Chemogenetic Activation of the dSep Increases Alcohol Intake in Male Mice.}

The primary objective of this experiment was to determine the effect of chemogenetic manipulation of the dSep on binge-like alcohol consumption. Alcohol drinking data $(\mathrm{g} / \mathrm{kg})$ for male and female mice harboring hM4Di, hM3Dq, or mCherry in the dSep when challenged with vehicle and CNO is shown in Fig. 2A. Mice were treated with vehicle and CNO prior to a 2-hr limited access drinking session in a within-subjects, counterbalanced design. Consistent with the literature, a main effect of $\operatorname{Sex}[F(1,43)=9.41, P=0.004]$ indicated that females generally consumed more alcohol than males in the DID model of binge drinking. A Sex*AAV interaction was observed $[F(2,43)=3.23, P=0.049]$ and the 3 -way Sex ${ }^{*} A \mathrm{~V}^{*}$ Drug interaction neared significance $[F(2,43)=2.58, P=0.088]$. Planned comparisons post hoc analysis revealed that male hM3Dq-exressing mice consumed significantly more alcohol (+0.91 g/kg, +/- 0.33) when treated with CNO compared to vehicle $(P=0.008)$. This effect was not observed after CNO challenge in female mice harboring hM3Dq in the dSep $(P=0.57)$. Silencing (hM4di) of the dSep did not affect alcohol drinking in male and female mice nor did CNO influence drinking in mCherry control groups (Ps> 0.3).

Drinking data were then analyzed as a percent change in alcohol intake for individual subjects relative to vehicle after $\mathrm{CNO}$ treatment (Fig. 2B). ANOVA revealed a near significant main effect of $\operatorname{AAV}[F(1,43)=3.14, P=0.053]$ and a Sex*AAV*Drug interaction $[F(1,43)=3.26, P=0.048]$. Post hoc analysis indicated that CNO treatment in hM3Dq-expressing mice resulted in an increase $(+52.03 \%$; +/ 13.3$)$ in alcohol consumption in males $(P<0.001)$ but did not influence drinking in females $(P=0.95)$. No effect was observed in male hM4Di and mCherry groups, nor in female hM4Di, hM3Dq, and mCherry groups (Ps>0.2). Together, these data suggest that activation of the dSep promoted alcohol drinking selectively in male mice.

\subsection{The dSep Bidirectionally Modulates Locomotor Activity in Male Mice.}

Because the septal region contributes to locomotion [26,44], mice were tested in an open field arena to assess the effect of dSep manipulation on cumulative locomotor activity (Fig. 3A). After habituation to the locomotor boxes, mice were challenged with vehicle and CNO in a counterbalanced, within-subjects design. ANOVA revealed a main effect of $\operatorname{AAV}[F(2,43)=5.35$, 
$P=0.008]$ and an $A A{ }^{*}$ Drug interaction $[F(2,43)=15.15, P<0.001]$. A Sex ${ }^{\star} A V^{*}$ Drug interaction $[F(2,43)=6.02, P=0.005]$ was observed and post hoc analysis indicated that locomotor activity was affected in male hM4Di- and hM3Dq-expressing groups after CNO challenge. More specifically, CNO resulted in a decrease in locomotor activity $(-1110.03 \mathrm{~cm} ;+/-470.26 ; P=0.023)$ in male mice harboring hM4Di in the dSep, and this effect neared significance in females ($1010.61 \mathrm{~cm} ;+/-533.23 ; \mathrm{P}=0.065)$. Activation $(\mathrm{hM} 3 \mathrm{Dq})$ of the dSep after CNO treatment resulted in an increase in locomotor activity $(+3164.28 \mathrm{~cm} ;+/-446.13)$ in males $(P<0.001)$ and was without effect in females $(P=0.63)$. Lastly, $C N O$ had no effect on locomotor activity in male and female mice expressing mCherry in the dSep (Ps> 0.7). Time spent in the center of the open field was calculated and shown in Supplemental Fig. 1A. Briefly, female mice generally spent less time in the center of the open field supported by a main effect of Sex $[F(1,43)=4.58, P=0.038]$. CNO did not affect center time $[F(1,43)=0.169, P=0.683]$ and post hoc indicated no differences in center time in any experimental condition when compared to CNO (Ps>0.2).

Analysis of locomotor activity when calculated as a percent change from vehicle indicated a similar pattern as cumulative distance traveled (Fig. 3B). There was a main effect of AAV [F (2, $43)=17.12, P<0.001]$ and $a S^{*} A^{*} V^{*}$ Drug interaction $[F(2,43)=6.47, P=0.003]$ indicating that locomotor activity was selectively impacted in male mice. Silencing (hM4Di) of the dSep decreased cumulative locomotor activity $(-35.65 \%,+/-12.5)$ in male mice $(P=0.007)$ but did not affect distance traveled in females $(P=0.14)$. In contrast, activation of the dSep increased locomotor activity $(+87.13 \%,+/-11.86)$ in males but was without effect in females $(P=0.38)$. Together, these data indicate a bidirectional effect of dSep manipulation selectively in male mice.

\subsection{Activation of the dSep Promotes Sucrose Drinking in Male and Female Mice.}

A final experiment was conducted to determine the effect of dSep manipulation on sucrose drinking (Fig. 4A). This experiment was conducted in a similar fashion to alcohol drinking, with vehicle and $\mathrm{CNO}$ being tested in a within-subjects, counterbalanced fashion. A main effect of Sex $[F(1,43)=99.89, P<0.001]$ indicated that females consumed significantly more sucrose than males in the 2-hr limited access drinking session. ANOVA also revealed an AAV*Drug interaction [F $(2,43)=4.19, P=0.022]$ and post hoc analysis supported an effect of dSep activation to increase sucrose drinking. Activation of the dSep promoted sucrose drinking $(+6.59 \mathrm{~mL} / \mathrm{kg} ;+/-$ $3.59)$ in male mice $(P=0.027)$ and a similar trend toward an increase in intake $(+10.62 \mathrm{~mL} / \mathrm{kg} ;+/-$ 4.63) was observed in females $(P=0.073)$. Silencing of the dSep did not affect sucrose drinking in male or female mice and CNO was without effect in mCherry conditions (Ps> 0.5).

Analysis of sucrose drinking data when expressed as a percent change in intake relative to vehicle support the effect of dSep activation to increase sucrose intake (Fig. 4B). ANOVA revealed an $\mathrm{AAV}^{*}$ Drug interaction $[F(2,43)=10.80, P<0.001]$ and further post hoc analysis support a general increase in sucrose drinking in male and female mice. More specifically, dSep activation resulted in an 83.70\% +/- 15.36 increase in sucrose drinking in males $(P<0.001)$ and an $47.59 \%+/-19.83$ increase in females $(P=0.021)$. Silencing of the dSep did not alter the relative change in sucrose drinking $(P s<0.2)$ nor did CNO alter intake in mCherry control groups (Ps>0.4).

\section{DISCUSSION}

The septal complex has been implicated in reward and various aspect of drug addiction, yet no studies have interrogated this structure in the context of binge-like alcohol consumption. Here, we report that chemogenetic activation (hM3Dq) of the dSep increased voluntary alcohol drinking in male mice in a modified-DID model. Alcohol intake was not affected in females, yet activation of the dSep resulted in increased sucrose drinking in both males and females 
suggesting a general role for the region in consummatory behavior. Silencing (hM4Di) of the dSep was without effect on alcohol or sucrose intake independent of sex. Lastly, activation or inhibition of the dSep increased/decreased locomotor activity respectively in males, but did not influence distance traveled in females. Therefore, the general increase in alcohol and sucrose intake in male mice may be due to a nonspecific increase in locomotor activity. Together, these data support a role for the dSep in promoting voluntary consumption of a palatable reward and suggests a role for the structure in alcohol drinking and locomotion in a sex-dependent fashion.

The septum is a centrally located subcortical limbic structure and is comprised of two distinct subregions: the lateral septum (LS) and medial septum (MS) [45]. The LS is situated in the dorsolateral region of the septal complex and is thought to promote goal directed behavior and learning by relaying spatial information from the hippocampus to the ventral tegmental area (VTA) for reward processing $[46,47]$. The present studies were planned to selectively target the LS yet rigorous histological review revealed an unexpected extension of mCherry expression into the dorsal edge of the MS. The MS is most well-known for its cholinergic contribution to septohippocmpal processing and involvement in the regulation of theta oscillations $[48,49]$. Breese and colleagues demonstrated MS responsivity to alcohol and a role for the structure in alcohol-induced sedation and seizure activity [36,50-52]. However, selective MS ablation resulted in increased water intake whereas LS ablation was without effect [53]. Stimulation of the MS conversely decreased drinking [54] suggesting bidirectional MS control over water intake that is in the opposite direction of the effects observed in the present studies. Thus, it is unlikely that the increase in alcohol drinking and sucrose intake after dSep activation is driven by the MS but we cannot attribute observed effects in our experiments to either the LS or MS alone. Discrete differentiation of the LS and MS is important for further study and identification of cell-types that promote drinking behavior will be of interest to the field.

Mechanistic study of the septal contribution to drug-seeking has been largely limited to cocaine and opioids $[40,41,55,56]$. However, there is ample evidence to suggest that the septal complex is responsive to alcohol. Alcohol generally suppresses c-fos activity within the septum and decreases catecholamine levels after both acute and chronic treatment $[34,35,57,58]$. However, findings are inconsistent in that intracerebroventricular alcohol infusion increased c-fos expression within the LS and promoted the development of a conditioned taste preference for a saccharin solution [59]. These findings suggest that alcohol promotes activity within the septum that is involved in reward processing and there is strong evidence supporting LS regulatory control over mesolimbic function. Indeed, the septum projects to both the VTA and NAc and these circuits have been hypothesized to promote reward-related behaviors [60,61], including excessive drinking behavior. Because pharmacological inactivation of the LS blocks the ability of alcohol to elevate extracellular dopamine within the NAc [62], it is reasonable to suspect that activation of the dSep in the present experiments could promote alcohol (and sucrose) intake through activation of canonical mesolimbic reward pathways. Furthermore, c-fos activity is elevated within the septum during withdrawal from alcohol suggesting that neuroadaptations occur within this structure over time [38]. The excessive alcohol drinking behavior observed after dSep activation is similar to the escalation of intake observed in dependence models and suggests a shared neurobiological mechanism. Another possible projection site of the dSep that modulates appetitive behavior is the hypothalamus. Both the LS and MS send projections to hypothalamic subregions and LS projections to the arcuate nucleus and lateral hypothalamus (LH) have been implicated in feeding [63] behavior and reinstatement of cocaine-seeking [40], respectively. The $\mathrm{LH}$ is of particular interest given that activation of GABAergic neurons therein promotes alcohol drinking and general consummatory behavior $[64,65]$. Thus, the VTA and LH serve as two likely downstream septal projection sites mediating alcohol drinking behavior. 
The septal complex is involved in locomotion and regulation of speed, velocity, and acceleration $[66,67]$. Our findings support previous work and indicates that the dSep exerts bidirectional control over locomotor activity in males. The septum, LS specifically, is hypothesized to drive a movement-value signal that is sent downstream to promote goal directed behavior [26]. In fact, hippocampal place-like cells within the LS are highly active in reward paired contexts [67] and manipulation can result in altered frequency and preservation of learned behaviors $[68,69]$. Thus, it is not surprising to see changes in locomotion in the open field task and this general increase in activity may present as increased consummatory behavior in the drinking tasks. Beyond this, if the septum is involved in reward learning and integration of movement involved in the behavior, dSep activation may promote drinking behavior by activating circuitry that enhances the valence of the rewarding stimulus, presenting as increased alcohol or sucrose drinking behavior.

Perhaps the most intriguing finding of the present study is that of sex differences in the outcome of dSep activation on alcohol and sucrose drinking behavior. Females generally consume more alcohol and sucrose than males in the DID model and there is much interest in identifying sexually dimorphic regions that promote this behavior [70-73]. Sex differences have been noted within the septum [74-76] and the ability of dSep activation to promote alcohol drinking in males is of particular interest. Here we report that dSep activation elevated alcohol intake in males (+52\%) to a level that matched intake in females. However, sucrose drinking was equally affected in males and females. It is possible that a ceiling effect was reached for alcohol consumption in females obscuring the potential to observe a hM3Dq-mediated increase in intake, and this possibility makes interpretation difficult. However, females consumed $3.4 \mathrm{~g} / \mathrm{kg}$ in 2-hrs and we have previously shown upwards of $4 \mathrm{~g} / \mathrm{kg}$ intake in C57BL/6J mice after pharmacological intervention [70], suggesting room to observe an increase in alcohol drinking. Lastly, it is surprising that dSep manipulation was without effect on locomotor activity in females. We have previously found greater distance traveled in female C57BL6/J mice under similar conditions in an open field arena [70] but no differences were observed in the present study. In contrast to previous work, mice were thoroughly habituated to the open field to allow for within-subjects testing and this may obscure heightened locomotion in females. Anxiety-like behavior, as determined through time spent in the center of the open field, remained unaffected by dSep manipulation. These data suggest that dSep activation promoted locomotor activity, but is not innately anxiogenic as others have speculated. Clearly, this single observation in the open field task is not conclusive, and habituation to the apparatus can confound this measure. However, the dSep likely functions to promote learned locomotor action linked to a specific context, and more complex assays for anxiety-like behavior linking the context to a specific outcome may be more appropriate for further septal interrogation.

The septum remains relatively understudied within modern alcohol research amidst a plethora of data supporting a role for the structure in behaviors and processes involved in the regulation of drinking behavior. Novel techniques within the preclinical toolkit allow for discrete manipulation of neuroanatomic targets such as the septal complex and the present findings indicate that the dSep plays a faciliatory role in promoting alcohol and sucrose drinking in sex-dependent fashion. However, much work is necessary to determine the exact mechanism that facilitates these effects. Because activation of the dSep increased alcohol drinking, an intriguing future direction is to determine if escalated alcohol intake in dependence models is dependent upon dSep activity. Lastly, discrete manipulation of the LS and MS and select cell-types within will be important for future studies. 
A)

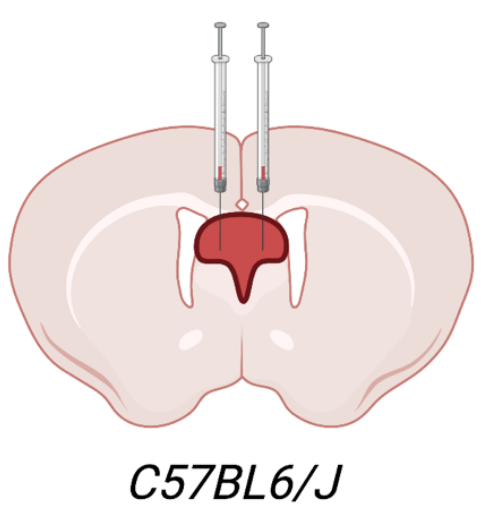

C)

\section{Week 1-3}

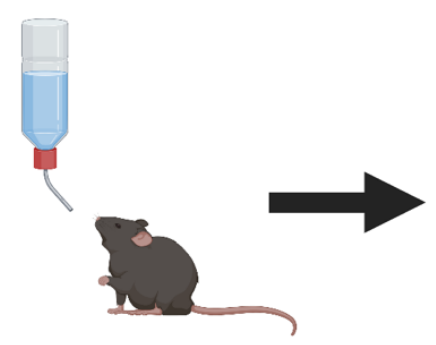

Alcohol Drinking (20\%; v/v)
B)

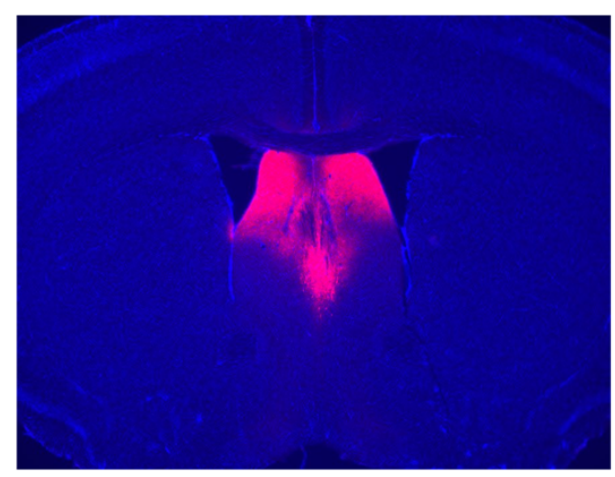

$\underline{\text { Week } 6}$

Week 7-8

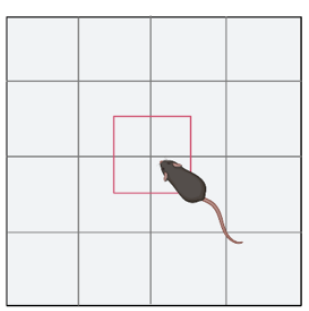

Open Field

30-min

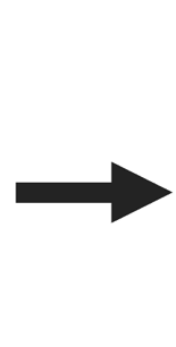

Sucrose Drinking

$(1 \% ; g / v)$

Figure 1: Viral Expression and Timeline of Experimental Procedures. A) AAVs harboring hM4Di, hM3Dq, or mCherry were infused into the dSep in male and female C57BL/6J mice 4 weeks prior to testing. B) Expression of mCherry was confined to the dorsal LS with some spillover into the dorsal edge of the MS. C) Experimental timeline depicting alcohol drinking, open field testing, and sucrose drinking. 
A)

B)

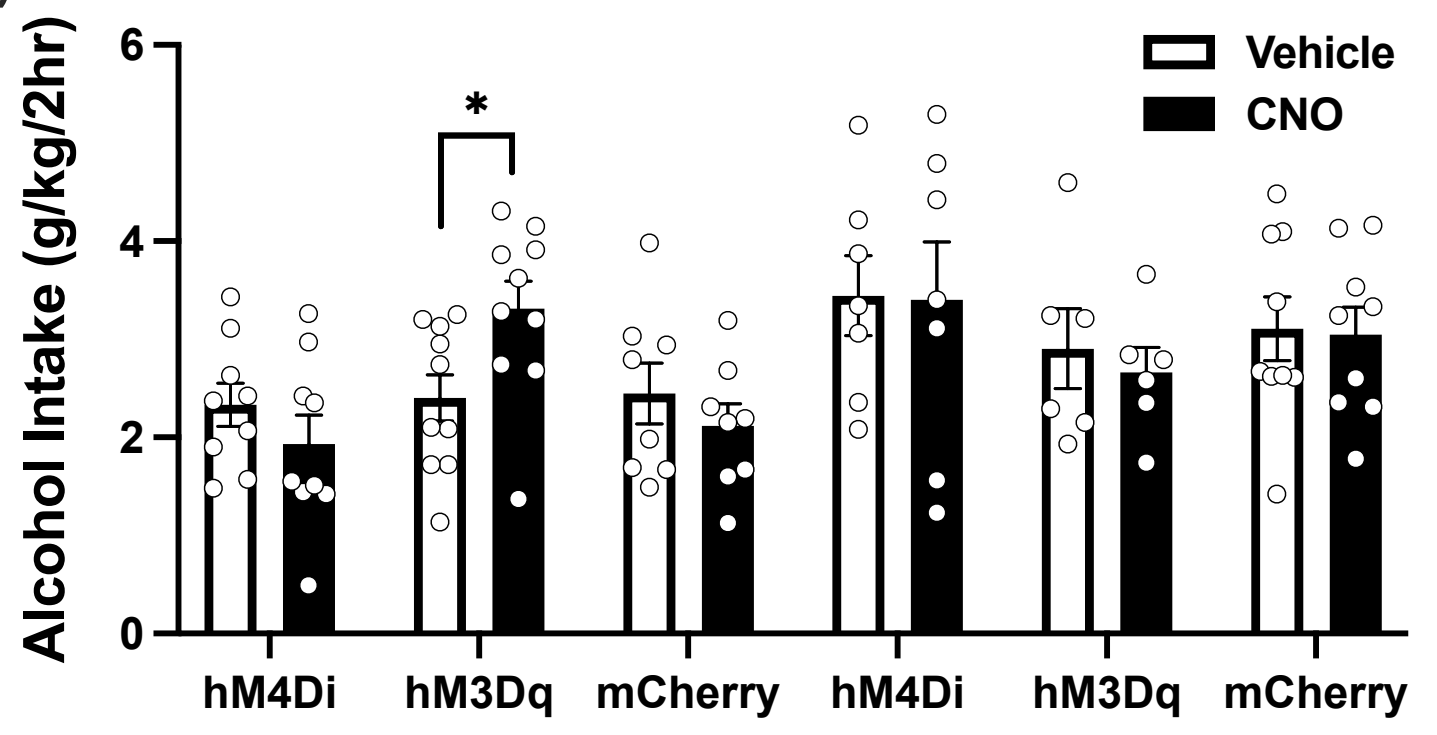

Male

Female

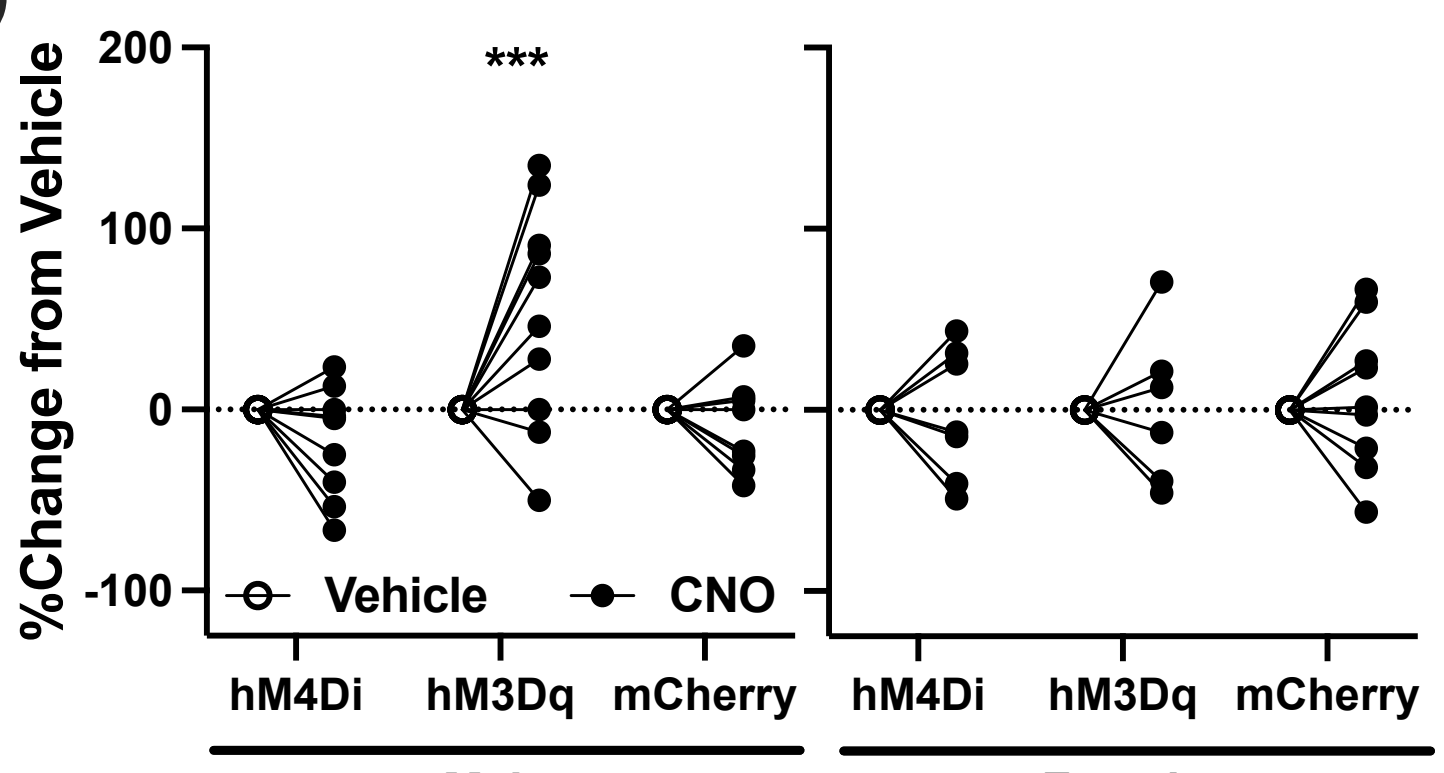

Male

Female

Figure 2: Chemogenetic Activation of the dSep Increases Alcohol Intake in Male Mice. A) Average alcohol intake $(\mathrm{g} / \mathrm{kg})$ after vehicle or CNO challenge. Alcohol drinking was greater in mice expressing hM3Dq in the dSep after CNO treatment when compared to vehicle $\left({ }^{*} \mathrm{P}=0.008\right)$. There was no effect of CNO treatment in the female hM3Dq group and CNO was without effect in hM4Di and mCherry conditions. B) Alcohol intake expressed as a percent change from vehicle after CNO challenge. Treatment with CNO in mice expressing hM3Dq within the dSep resulted in a significant increase in alcohol intake in males relative to vehicle $\left({ }^{* * *} P<0.001\right)$. No significant change in intake was observed in hM4Di- or mCherry-expressing males. Lastly, there was no effect of experimental manipulation on the relative change in alcohol intake in female mice. 
A)

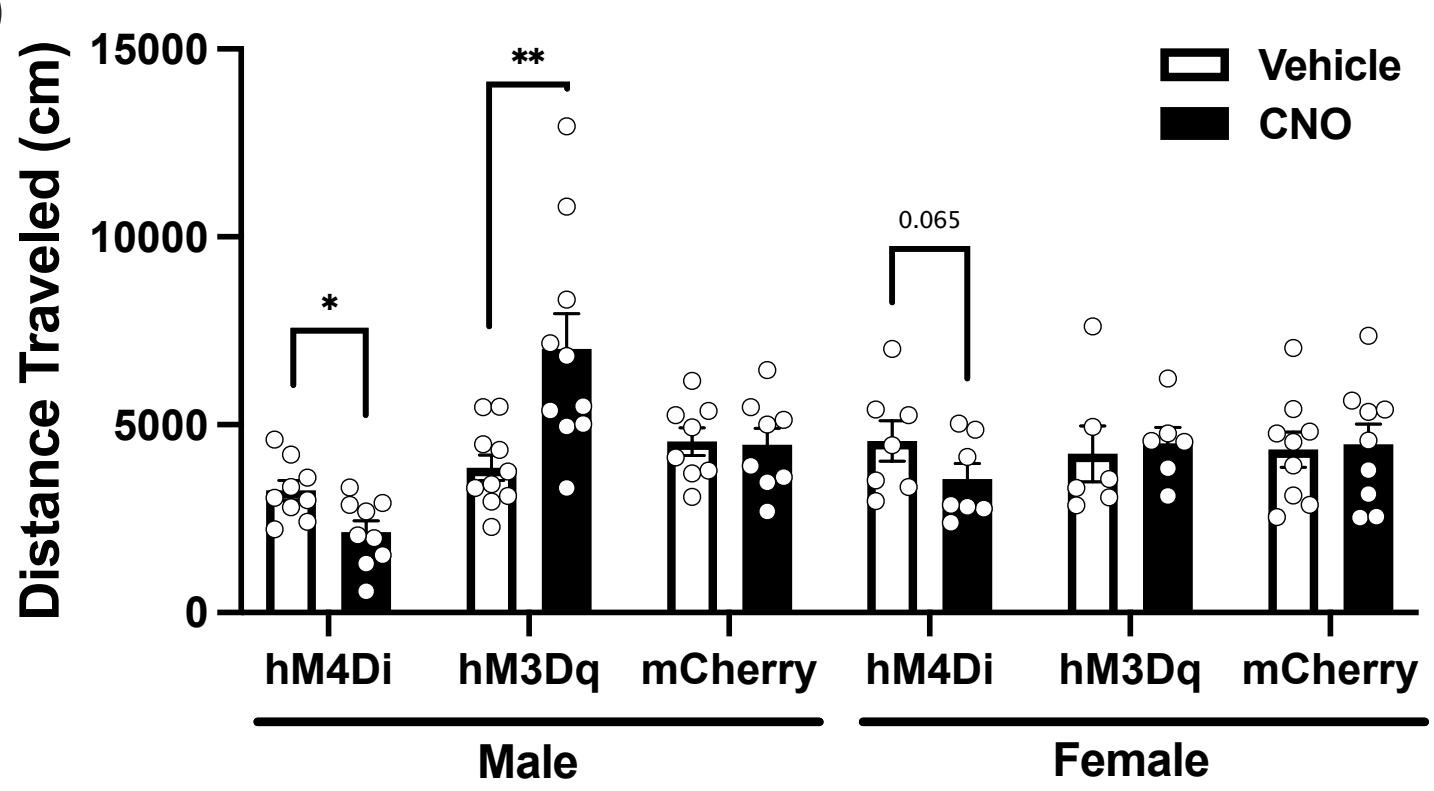

B)

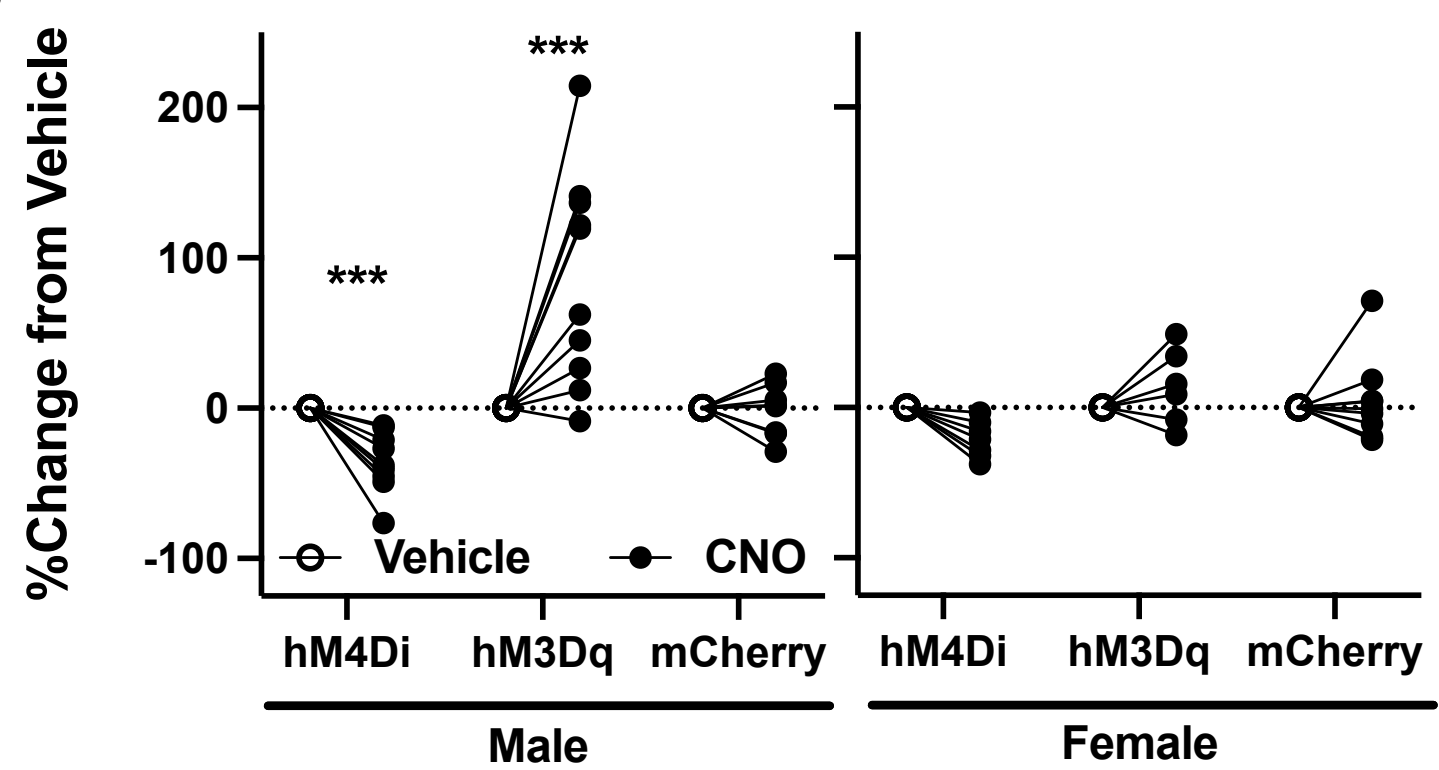

Figure 3: The dSep Bidirectionally Modulates Locomotor Activity in Male Mice. A) Cumulative distance traveled $(\mathrm{cm})$ during an open field test. Compared to vehicle, CNO treatment resulted in lower distance traveled in male mice expressing hM4Di in the dSep compared to vehicle ( ${ }^{*} \mathrm{P}=$ 0.023). Greater distance traveled was observed in the male hM3Dq group compared to vehicle $\left({ }^{*} P<0.001\right)$. Female groups were not affected by $C N O$ although there was a trend toward a decrease in distance traveled in the $\mathrm{hM} 4 \mathrm{Di}$ condition $(\mathrm{P}=0.065)$. B) Locomotor activity expressed as a percent change from vehicle after $\mathrm{CNO}$ challenge. Treatment with $\mathrm{CNO}$ in mice expressing $\mathrm{hM} 4 \mathrm{Di}$ within the dSep resulted in a significant decrease in locomotor activity relative to vehicle in males $\left({ }^{* * *} \mathrm{P}<0.001\right)$. Conversely, activation of the dSep in males expressing $\mathrm{hM} 3 \mathrm{Dq}$ resulted in increased locomotor activity $\left({ }^{* * *} P<0.001\right)$. No significant change in locomotion was observed in female mice. 
A)

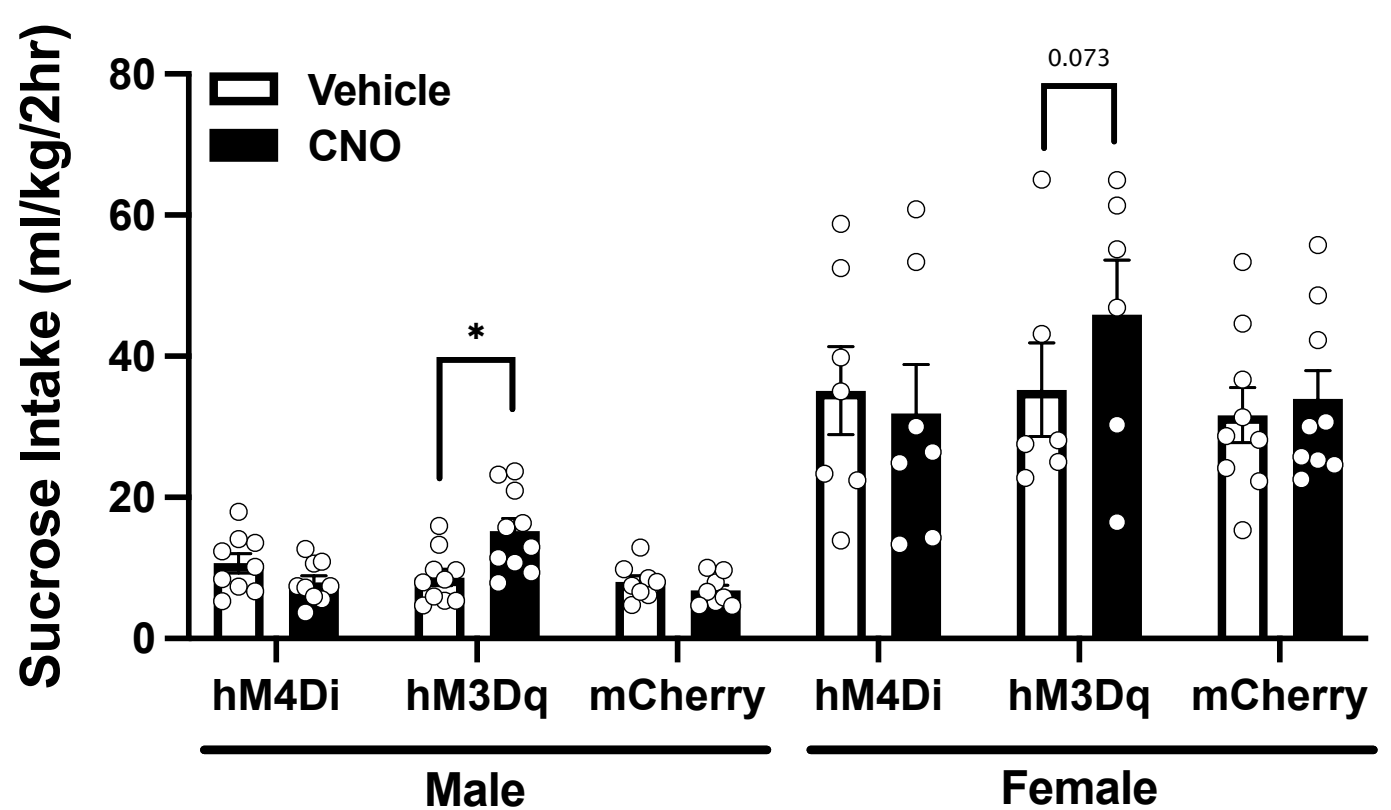

B)

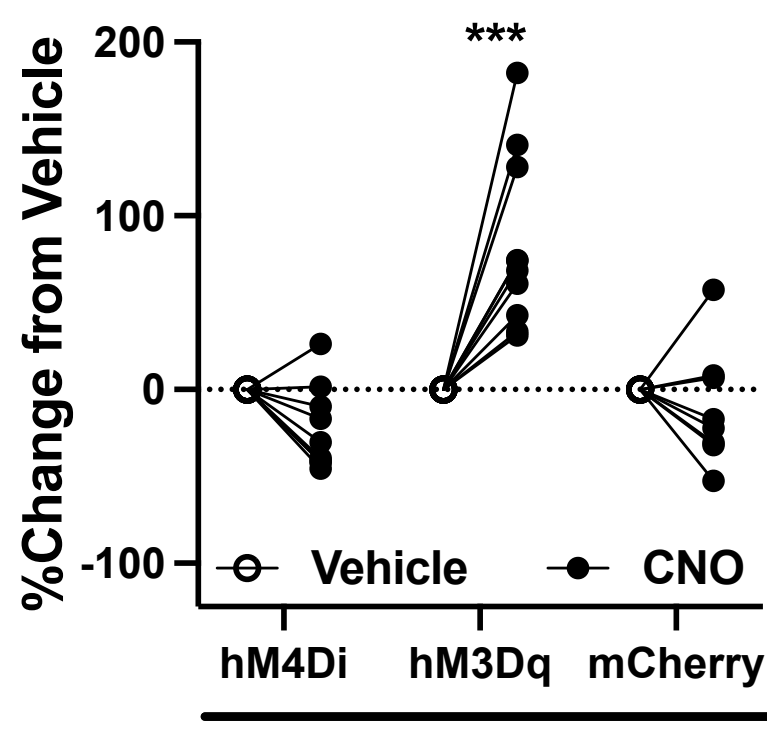

Male

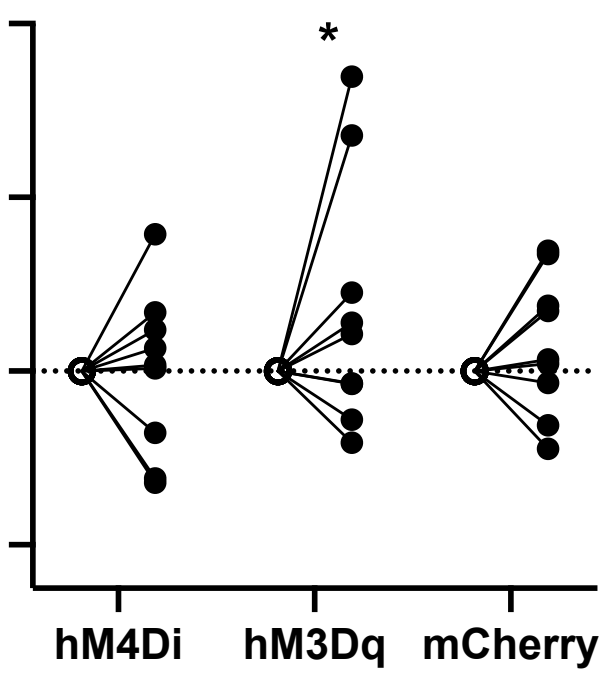

Female

Figure 4: Activation of the dSep Promotes Sucrose Drinking in Male and Female Mice. A) Sucrose intake $(\mathrm{ml} / \mathrm{kg})$ after vehicle or CNO challenge. Sucrose drinking was significantly greater after treatment with CNO in male mice expressing hM3Dq within the dSep $\left({ }^{*} P=0.008\right)$ and this effect neared significance in females $(P=0.073)$. There was no effect of CNO in hM4Di and mCherry conditions. B) Sucrose intake expressed as a percent change from vehicle after CNO challenge. Treatment with $\mathrm{CNO}$ in mice expressing $\mathrm{hM} 3 \mathrm{Dq}$ within the dSep resulted in a significant increase in sucrose consumption relative to vehicle in males $\left({ }^{* *} P<0.001\right)$ and females $\left({ }^{*} \mathrm{P}=0.021\right)$. There was no change in sucrose intake in hM4Di or mCherry conditions. 
A)

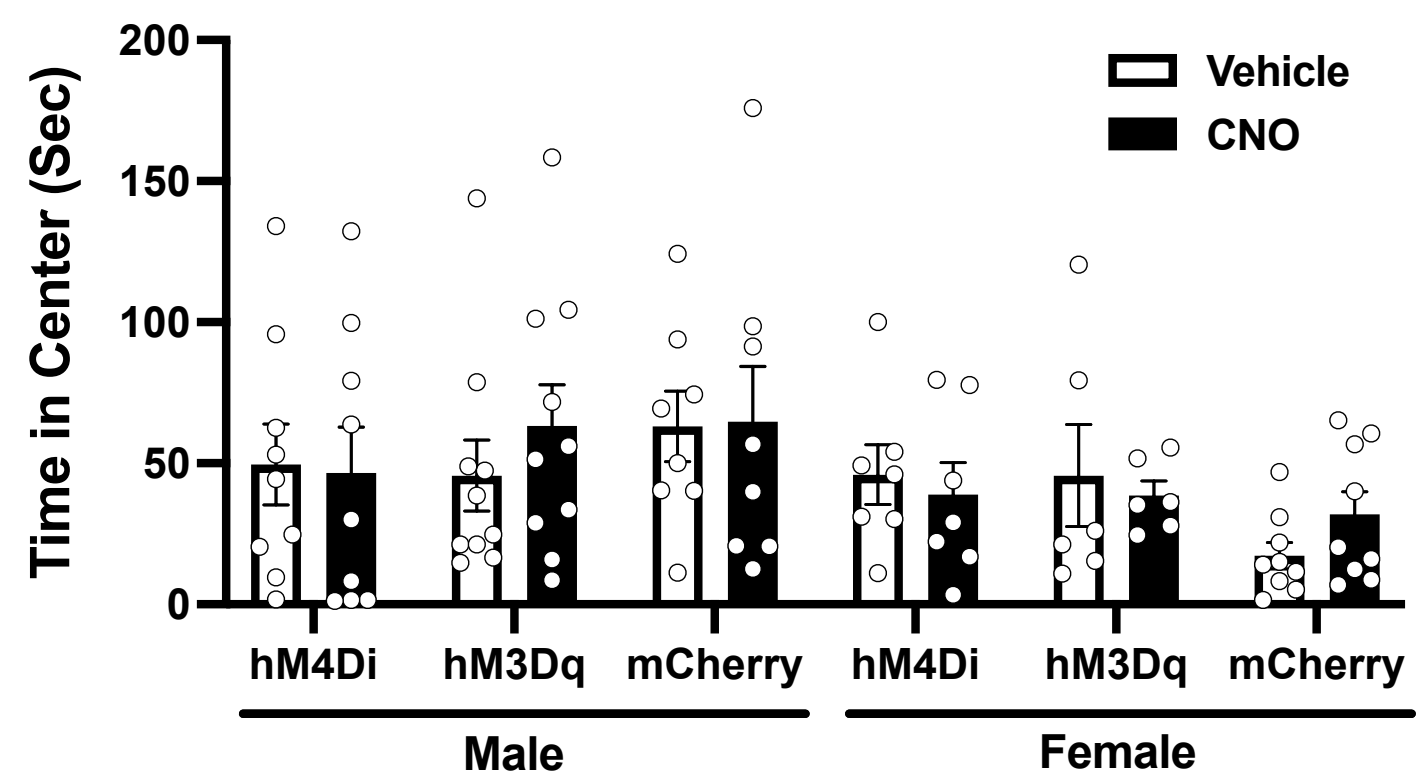

B)

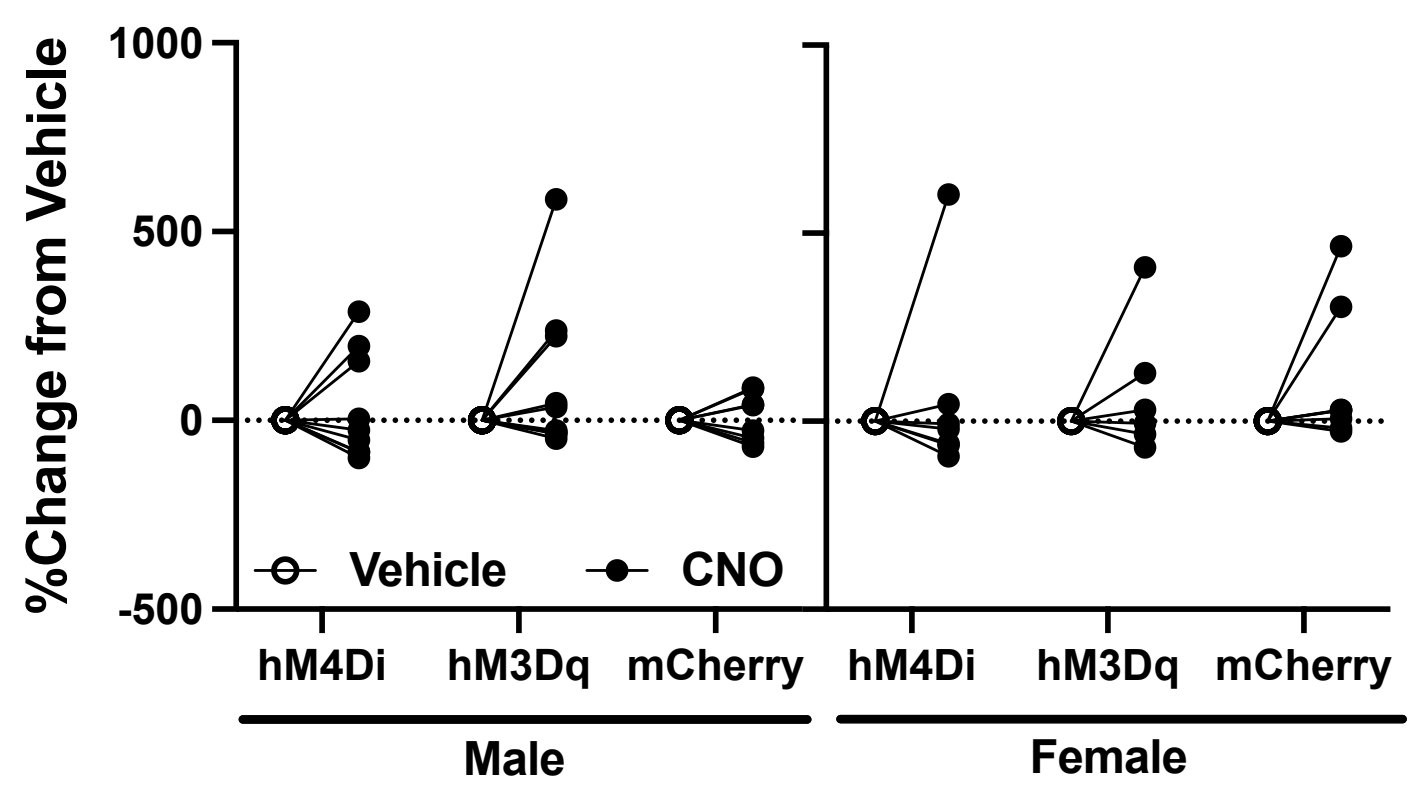

Supplemental Figure 1. Manipulation of the dSep Does Not Affect Anxiety-Like Behavior in an Open Field Arena. A) Cumulative spent in the center of the open field. No differences were detected in any condition after $\mathrm{CNO}$ challenge. However, females generally exhibited less center time than males $(P=0.038)$. B) Time spent in center expressed as a change relative to vehicle. CNO treatment did not significantly alter center time in any experimental condition. 


\section{ACKNOWLEDGMENTS}

Graphical abstract was created with BioRender.

\section{FUNDING SOURCES}

This work was funded by National Institute on Alcohol Abuse and Alcoholism (NIAAA) Grants T32 AA007573 (F.T.C), R01 AA019454 (T.L.K.), and U01 P60 AA011605 (T.L.K.).

\section{DISCLOSURES}

No conflicts of interest, financial or otherwise, are declared by the authors. 


\section{REFERENCES}

[1] Weerakoon SM, Jetelina KK \& Knell G. Longer time spent at home during COVID-19 pandemic is associated with binge drinking among US adults. Am J Drug Alcohol Abuse 47(1):98-106, 2021.

[2] Xiong J, Lipsitz O, Nasri F, Lui LMW, Gill H, Phan L, Chen-Li D, Iacobucci M, Ho R, Majeed A \& McIntyre RS. Impact of COVID-19 pandemic on mental health in the general population: A systematic review. J Affect Disord 277:55-64, 2020. PMCID: PMC7413844

[3] Kanny D, Liu Y, Brewer RD, Lu H, Centers for Disease C \& Prevention. Binge drinking - United States, 2011. MMWR Suppl 62(3):77-80, 2013.

[4] Courtney KE \& Polich J. Binge drinking in young adults: Data, definitions, and determinants. Psychol Bull 135(1):142-156, 2009. PMCID: PMC2748736

[5] SAMHSA SAaMHSA. In Facing Addiction in America: The Surgeon General's Report on Alcohol, Drugs, and Health, Reports of the Surgeon General, Washington (DC), 2016.

[6] WHO. Global status report on alcohol and health. Geneva, Switzerland: World Health Organization, pp volumes, 2018.

[7] Bedendo A, Andrade ALM, Opaleye ES \& Noto AR. Binge drinking: a pattern associated with a risk of problems of alcohol use among university students. Rev Lat Am Enfermagem 25:e2925, 2017. PMCID: PMC5599070

[8] Gowin JL, Sloan ME, Stangl BL, Vatsalya V \& Ramchandani VA. Vulnerability for Alcohol Use Disorder and Rate of Alcohol Consumption. Am J Psychiatry 174(11):10941101, 2017. PMCID: PMC5667663

[9] Hingson RW, Zha W \& White AM. Drinking Beyond the Binge Threshold: Predictors, Consequences, and Changes in the U.S. Am J Prev Med 52(6):717-727, 2017.

[10] Naimi TS, Brewer RD, Mokdad A, Denny C, Serdula MK \& Marks JS. Binge drinking among US adults. JAMA 289(1):70-75, 2003.

[11] Sacks JJ, Gonzales KR, Bouchery EE, Tomedi LE \& Brewer RD. 2010 National and State Costs of Excessive Alcohol Consumption. Am J Prev Med 49(5):e73-e 79, 2015.

[12] Dwyer-Lindgren L, Bertozzi-Villa A, Stubbs RW, Morozoff C, Kutz MJ, Huynh C, Barber RM, Shackelford KA, Mackenbach JP, van Lenthe FJ, Flaxman AD, Naghavi M, Mokdad AH \& Murray CJ. US County-Level Trends in Mortality Rates for Major Causes of Death, 1980-2014. JAMA 316(22):2385-2401, 2016. PMCID: PMC5576343

[13] Mokdad AH, Marks JS, Stroup DF \& Gerberding JL. Actual causes of death in the United States, 2000. JAMA 291(10):1238-1245, 2004.

[14] Rhodes JS, Best K, Belknap JK, Finn DA \& Crabbe JC. Evaluation of a simple model of ethanol drinking to intoxication in C57BL/6J mice. Physiol Behav 84(1):53-63, 2005.

[15] Sprow GM \& Thiele TE. The neurobiology of binge-like ethanol drinking: evidence from rodent models. Physiol Behav 106(3):325-331, 2012. PMCID: PMC3348336

[16] Crabbe JC, Ozburn AR, Metten P, Barkley-Levenson A, Schlumbohm JP, Spence SE, Hack WR \& Huang LC. High Drinking in the Dark (HDID) mice are sensitive to the effects of some clinically relevant drugs to reduce binge-like drinking. Pharmacol Biochem Behav 160:55-62, 2017. PMCID: PMC5603423

[17] Marchant NJ, Campbell EJ, Whitaker LR, Harvey BK, Kaganovsky K, Adhikary S, Hope BT, Heins RC, Prisinzano TE, Vardy E, Bonci A, Bossert JM \& Shaham Y. Role of 
Ventral Subiculum in Context-Induced Relapse to Alcohol Seeking after PunishmentImposed Abstinence. J Neurosci 36(11):3281-3294, 2016. PMCID: PMC4792939

[18] Grifasi IR, McIntosh SE, Thomas RD, Lysle DT, Thiele TE \& Marshall SA. Characterization of the Hippocampal Neuroimmune Response to Binge-Like Ethanol Consumption in the Drinking in the Dark Model. Neuroimmunomodulation 26(1):19-32, 2019. PMCID: PMC6389401

[19] Anderson RI, Lopez MF, Griffin WC, Haun HL, Bloodgood DW, Pati D, Boyt KM, Kash TL \& Becker HC. Dynorphin-kappa opioid receptor activity in the central amygdala modulates binge-like alcohol drinking in mice. Neuropsychopharmacology 2018.

[20] Haaranen M, Schafer A, Jarvi V \& Hyytia P. Chemogenetic Stimulation and Silencing of the Insula, Amygdala, Nucleus Accumbens, and Their Connections Differentially Modulate Alcohol Drinking in Rats. Front Behav Neurosci 14:580849, 2020. PMCID: PMC7671963

[21] Purohit K, Parekh PK, Kern J, Logan RW, Liu Z, Huang Y, McClung CA, Crabbe JC \& Ozburn AR. Pharmacogenetic Manipulation of the Nucleus Accumbens Alters BingeLike Alcohol Drinking in Mice. Alcohol Clin Exp Res 42(5):879-888, 2018. PMCID: PMC6034712

[22] Pozhidayeva DY, Farris SP, Goeke CM, Firsick EJ, Townsley KG, Guizzetti M \& Ozburn AR. Chronic Chemogenetic Stimulation of the Nucleus Accumbens Produces Lasting Reductions in Binge Drinking and Ameliorates Alcohol-Related Morphological and Transcriptional Changes. Brain Sci 10(2) 2020. PMCID: PMC7071376

[23] Olds J \& Milner P. Positive reinforcement produced by electrical stimulation of septal area and other regions of rat brain. J Comp Physiol Psychol 47(6):419-427, 1954.

[24] Albert DJ, Brayley KN \& Milner JA. Connections from the lateral septum modulating reactivity in the rat. Physiol Behav 21(5):761-767, 1978.

[25] Albert DJ \& Wong RC. Hyperreactivity, muricide, and intraspecific aggression in the rat produced by infusion of local anesthetic into the lateral septum or surrounding areas. $J$ Comp Physiol Psychol 92(6):1062-1073, 1978.

[26] Wirtshafter HS \& Wilson MA. Lateral septum as a nexus for mood, motivation, and movement. Neurosci Biobehav Rev 126:544-559, 2021.

[27] Neiman J, Lang AE, Fornazzari L \& Carlen PL. Movement disorders in alcoholism: a review. Neurology 40(5):741-746, 1990.

[28] Paelecke-Habermann Y, Paelecke M, Mauth J, Tschisgale J, Lindenmeyer J \& Kubler A. A comparison of implicit and explicit reward learning in low risk alcohol users versus people who binge drink and people with alcohol dependence. Addict Behav Rep 9:100178, 2019. PMCID: PMC6542748

[29] Koob GF \& Le Moal M. Plasticity of reward neurocircuitry and the 'dark side' of drug addiction. Nat Neurosci 8(11):1442-1444, 2005.

[30] WHO. Expert Committee on Problems Related to Alcohol Consumption. World Health Organ Tech Rep Ser (944):1-53, 55-57, back cover, 2007.

[31] Pollock VE, Schneider LS, Zemansky MF, Gleason RP \& Pawluczyk S. Topographic quantitative EEG amplitude in recovered alcoholics. Psychiatry Res 45(1):25-32, 1992.

[32] Sullivan EV \& Pfefferbaum A. Neuroimaging of the Wernicke-Korsakoff syndrome. Alcohol Alcohol 44(2):155-165, 2009. PMCID: PMC2724861 
[33] Sullivan EV, Deshmukh A, De Rosa E, Rosenbloom MJ \& Pfefferbaum A. Striatal and forebrain nuclei volumes: contribution to motor function and working memory deficits in alcoholism. Biol Psychiatry 57(7):768-776, 2005.

[34] Bachtell RK, Weitemier AZ, Galvan-Rosas A, Tsivkovskaia NO, Risinger FO, Phillips TJ, Grahame NJ \& Ryabinin AE. The Edinger-Westphal-lateral septum urocortin pathway and its relationship to alcohol consumption. J Neurosci 23(6):2477-2487, 2003. PMCID: PMC6742045

[35] Ryabinin AE, Galvan-Rosas A, Bachtell RK \& Risinger FO. High alcohol/sucrose consumption during dark circadian phase in C57BL/6J mice: involvement of hippocampus, lateral septum and urocortin-positive cells of the Edinger-Westphal nucleus. Psychopharmacology (Berl) 165(3):296-305, 2003.

[36] Givens BS \& Breese GR. Electrophysiological evidence that ethanol alters function of medial septal area without affecting lateral septal function. J Pharmacol Exp Ther 253(1):95-103, 1990. PMCID: PMC3014606

[37] Criswell HE, Simson PE, Knapp DJ, Devaud LL, McCown TJ, Duncan GE, Morrow AL \& Breese GR. Effect of zolpidem on gamma-aminobutyric acid (GABA)-induced inhibition predicts the interaction of ethanol with GABA on individual neurons in several rat brain regions. J Pharmacol Exp Ther 273(1):526-536, 1995.

[38] Knapp DJ, Duncan GE, Crews FT \& Breese GR. Induction of Fos-like proteins and ultrasonic vocalizations during ethanol withdrawal: further evidence for withdrawalinduced anxiety. Alcohol Clin Exp Res 22(2):481-493, 1998.

[39] Sartor GC \& Aston-Jones GS. A septal-hypothalamic pathway drives orexin neurons, which is necessary for conditioned cocaine preference. J Neurosci 32(13):4623-4631, 2012. PMCID: PMC3350779

[40] McGlinchey EM \& Aston-Jones G. Dorsal Hippocampus Drives Context-Induced Cocaine Seeking via Inputs to Lateral Septum. Neuropsychopharmacology 43(5):9871000, 2018. PMCID: PMC5854789

[41] Pantazis CB \& Aston-Jones G. Lateral septum inhibition reduces motivation for cocaine: Reversal by diazepam. Addict Biol 25(2):e12742, 2020. PMCID: PMC6754816

[42] Haun HL, Griffin WC, Lopez MF, Solomon MG, Mulholland PJ, Woodward JJ, McGinty JF, Ron D \& Becker HC. Increasing Brain-Derived Neurotrophic Factor (BDNF) in medial prefrontal cortex selectively reduces excessive drinking in ethanol dependent mice. Neuropharmacology 140:35-42, 2018. PMCID: PMC6113096

[43] Dornellas APS, Burnham NW, Luhn KL, Petruzzi MV, Thiele TE \& Navarro M. Activation of locus coeruleus to rostromedial tegmental nucleus (RMTg) noradrenergic pathway blunts binge-like ethanol drinking and induces aversive responses in mice. Neuropharmacology 199:108797, 2021. PMCID: PMC8583311

[44] Bender F, Gorbati M, Cadavieco MC, Denisova N, Gao X, Holman C, Korotkova T \& Ponomarenko A. Theta oscillations regulate the speed of locomotion via a hippocampus to lateral septum pathway. Nat Commun 6:8521, 2015. PMCID: PMC4633825

[45] Fried PA. Septum and behavior: a review. Psychol Bull 78(4):292-310, 1972.

[46] Deng K, Yang L, Xie J, Tang H, Wu GS \& Luo HR. Whole-brain mapping of projection from mouse lateral septal nucleus. Biol Open 8(7) 2019. PMCID: PMC6679409

[47] Varoqueaux F \& Poulain P. Projections of the mediolateral part of the lateral septum to the hypothalamus, revealed by Fos expression and axonal tracing in rats. Anat Embryol (Berl) 199(3):249-263, 1999. 
[48] Muller C \& Remy S. Septo-hippocampal interaction. Cell Tissue Res 373(3):565-575, 2018. PMCID: PMC6132648

[49] Vertes RP \& Kocsis B. Brainstem-diencephalo-septohippocampal systems controlling the theta rhythm of the hippocampus. Neuroscience 81(4):893-926, 1997.

[50] McCown TJ, Moray LJ, Kizer JS \& Breese GR. Interactions between TRH and ethanol in the medial septum. Pharmacol Biochem Behav 24(5):1269-1274, 1986. PMCID: PMC3012330

[51] Breese GR, Frye GD, McCown TJ \& Mueller RA. Comparison of the CNS effects induced by TRH and bicuculline after microinjection into medial septum, substantia nigra and inferior colliculus: absence of support for a GABA antagonist action for TRH. Pharmacol Biochem Behav 21(1):145-149, 1984. PMCID: PMC2913876

[52] Frye GD, McCown TJ \& Breese GR. Characterization of susceptibility to audiogenic seizures in ethanol-dependent rats after microinjection of gamma-aminobutyric acid (GABA) agonists into the inferior colliculus, substantia nigra or medial septum. $J$ Pharmacol Exp Ther 227(3):663-670, 1983. PMCID: PMC3310216

[53] Liao RM \& Yeh CC. Influences on water intake in the rat after lesions of the septal subareas. Proc Natl Sci Counc Repub China B 24(1):26-32, 2000.

[54] Moran JS \& Blass EM. Inhibition of drinking by septal stimulation in rats. Physiol Behav 17(1):23-27, 1976.

[55] Le Merrer J, Gavello-Baudy S, Galey D \& Cazala P. Morphine self-administration into the lateral septum depends on dopaminergic mechanisms: Evidence from pharmacology and Fos neuroimaging. Behav Brain Res 180(2):203-217, 2007.

[56] Ciccarelli A, Calza A, Santoru F, Grasso F, Concas A, Sassoe-Pognetto M \& Giustetto M. Morphine withdrawal produces ERK-dependent and ERK-independent epigenetic marks in neurons of the nucleus accumbens and lateral septum. Neuropharmacology 70:168-179, 2013.

[57] Walker DW, Heaton MB, Lee N, King MA \& Hunter BE. Effect of chronic ethanol on the septohippocampal system: a role for neurotrophic factors? Alcohol Clin Exp Res 17(1):12-18, 1993.

[58] Titkova AM \& Epstein OI. Effect of preparations from potentiated ethanol on the content of biogenic monoamines and metabolism of ethanol in tissues of rats during alcoholization. Bull Exp Biol Med 135 Suppl 7:36-38, 2003.

[59] Crankshaw DL, Briggs JE, Olszewski PK, Shi Q, Grace MK, Billington CJ \& Levine AS. Effects of intracerebroventricular ethanol on ingestive behavior and induction of c-Fos immunoreactivity in selected brain regions. Physiol Behav 79(1):113-120, 2003.

[60] Luo AH, Tahsili-Fahadan P, Wise RA, Lupica CR \& Aston-Jones G. Linking context with reward: a functional circuit from hippocampal CA3 to ventral tegmental area. Science 333(6040):353-357, 2011. PMCID: PMC3150711

[61] Vega-Quiroga I, Yarur HE \& Gysling K. Lateral septum stimulation disinhibits dopaminergic neurons in the antero-ventral region of the ventral tegmental area: Role of GABA-A alpha 1 receptors. Neuropharmacology 128:76-85, 2018.

[62] Jonsson S, Morud J, Stomberg R, Ericson M \& Soderpalm B. Involvement of lateral septum in alcohol's dopamine-elevating effect in the rat. Addict Biol 22(1):93-102, 2017.

[63] Azevedo EP, Tan B, Pomeranz LE, Ivan V, Fetcho R, Schneeberger M, Doerig KR, Liston C, Friedman JM \& Stern SA. A limbic circuit selectively links active escape to food suppression. Elife 9 2020. PMCID: PMC7476759 
[64] Burnham NW, Chaimowitz CN, Vis CC, Segantine Dornellas AP, Navarro M \& Thiele TE. Lateral hypothalamus-projecting noradrenergic locus coeruleus pathway modulates binge-like ethanol drinking in male and female TH-ires-cre mice. Neuropharmacology 196:108702, 2021. PMCID: PMC8434995

[65] Navarro M, Olney JJ, Burnham NW, Mazzone CM, Lowery-Gionta EG, Pleil KE, Kash TL \& Thiele TE. Lateral Hypothalamus GABAergic Neurons Modulate Consummatory Behaviors Regardless of the Caloric Content or Biological Relevance of the Consumed Stimuli. Neuropsychopharmacology 41(6):1505-1512, 2016. PMCID: PMC4832010

[66] van der Veldt S, Etter G, Mosser CA, Manseau F \& Williams S. Conjunctive spatial and self-motion codes are topographically organized in the GABAergic cells of the lateral septum. PLoS Biol 19(8):e3001383, 2021. PMCID: PMC8432898

[67] Wirtshafter HS \& Wilson MA. Locomotor and Hippocampal Processing Converge in the Lateral Septum. Curr Biol 29(19):3177-3192 e3173, 2019.

[68] Sagvolden T. Free-operant avoidance behavior in rats with lateral septal lesions: Effect of shock intensity. Brain Res 110(3):559-574, 1976.

[69] Vouimba RM, Garcia R \& Jaffard R. Opposite effects of lateral septal LTP and lateral septal lesions on contextual fear conditioning in mice. Behav Neurosci 112(4):875-884, 1998.

[70] Haun HL, Griffin WC, Lopez MF \& Becker HC. Kappa opioid receptors in the bed nucleus of the stria terminalis regulate binge-like alcohol consumption in male and female mice. Neuropharmacology 167:107984, 2020. PMCID: PMC7080606

[71] Nentwig TB, Wilson DE, Rhinehart EM \& Grisel JE. Sex differences in binge-like EtOH drinking, corticotropin-releasing hormone and corticosterone: effects of beta-endorphin. Addict Biol 24(3):447-457, 2019. PMCID: PMC6082742

[72] Sneddon EA, White RD \& Radke AK. Sex Differences in Binge-Like and AversionResistant Alcohol Drinking in C57BL/6J Mice. Alcohol Clin Exp Res 43(2):243-249, 2019.

[73] Satta R, Hilderbrand ER \& Lasek AW. Ovarian Hormones Contribute to High Levels of Binge-Like Drinking by Female Mice. Alcohol Clin Exp Res 42(2):286-294, 2018. PMCID: PMC5785425

[74] De Vries GJ, Best W \& Sluiter AA. The influence of androgens on the development of a sex difference in the vasopressinergic innervation of the rat lateral septum. Brain Res 284(2-3):377-380, 1983.

[75] Tsukahara S, Kanaya M \& Yamanouchi K. Neuroanatomy and sex differences of the lordosis-inhibiting system in the lateral septum. Front Neurosci 8:299, 2014. PMCID: PMC4166118

[76] Oliveira VEM, Lukas M, Wolf HN, Durante E, Lorenz A, Mayer AL, Bludau A, Bosch OJ, Grinevich V, Egger V, de Jong TR \& Neumann ID. Oxytocin and vasopressin within the ventral and dorsal lateral septum modulate aggression in female rats. Nat Commun 12(1):2900, 2021. PMCID: PMC8131389 